\title{
La experiencia de Dios en personas que viven con $\mathrm{VIH} / \mathrm{Sida}^{*}$
}

\author{
Nelson Mafla Terán“ \\ Pontificia Universidad Javeriana \\ Colombia \\ Edith González Bernal** \\ Pontificia Universidad Javeriana \\ Colombia
}

Para citar este artículo: González Bernal, Edith y Mafla Terán, Nelson.

«La experiencia de Dios en personas que viven con VIH/Sida».

Fraciscanum 169, Vol. LX (2018): 273-309.

\section{Resumen}

Este texto presenta la interpretación de la experiencia de Dios que tiene un grupo de portadores de vIH-SIDA. La pregunta que orientó la indagación fue ¿̇cómo configuran, una experiencia de Dios, las personas que viven con viH-SIDA? Cabe aclarar que las personas que aportaron sus experiencias son en su mayoría homosexuales, esta cuestión por sí misma constituye un planteamiento vigente para

Artículo como resultado de la investigación «La experiencia de Dios en la corporeidad y la sexualidad de pacientes que viven con VIH-SIDA» realizado en asocio entre la iglesia sueca Luterana y la facultad de Teología de la Pontificia Universidad Javeriana de Bogotá.

Doctor en Ciencias de las religiones Universidad Complutense de Madrid. Diploma de Estudios Avanzados en el área de Antropología Social, Universidad Complutense de Madrid. Magister en Teología y Licenciado en Ciencias Religiosas de la Pontificia Universidad Javeriana. Profesor del Centro de Formación Teológica de la Pontificia Universidad Javeriana de Bogotá. Código ORCID 0000-0002-5747-4464. Contacto: nelson.mafla@javeriana.edu.co.

... Doctora en Teología, teóloga, Baccalaureato en teología y Magistra de la Pontificia Universidad Javeriana. Doctora en Ciencias de la Educación, Universidad Pedagógica y Tecnológica de Colombia. Profesora del Departamento de Teología de la Pontificia Universidad Javeriana. Código ORCID 0000-0002-5143-1068. Contacto: edith.gonzalez@javeriana.edu.co. 
la teología moral. En este escrito se profundiza en las categorías corporeidad, sexualidad y homosexualidad, como categorías relevantes para enfrentar la vida e interpretar la experiencia de Dios. El método que posibilitó esta indagación fue la Investigación Acción Participativa-IAP, en la que investigadores e investigados leyeron su experiencia en medio de la adversidad y encontraron la presencia de un Dios que se manifiesta misericordioso y ajeno a prejuicios humanos.

\title{
Palabras clave
}

Experiencia de Dios, sexualidad, viH-SIDA, homosexualidad, Investigación Acción Participativa.

\section{The experience of God in people who live with HIV/AIDS}

\begin{abstract}
This paper presents the interpretation of the experience of God given by a group of HIV/AIDS carriers. The question that guided this investigation was: How do people who live with AIDs configure an experience of God? It is worth mentioning that the people who contributed with their experience are mostly homosexual, this matter is, by itself, a prevailing enquiry for moral theology. This paper addresses corporeity, sexuality and homosexuality, as categories relevant to facing life and understanding the experience of God. This investigation was possible thanks to the Participatory Action Research (PAR) approach, in which both researchers and participants read their own experience amidst adversity and found the presence of a God who manifests himself as merciful and oblivious to human prejudice.
\end{abstract}




\section{Key words}

Experience of God, sexuality, HIV-AIDS, homosexuality, Participatory Action Research.

\section{Introducción}

Este artículo aborda las categorías: experiencia de Dios, corporeidad y sexualidad. Aquí, nos ocupamos específicamente de ícómo configuran las personas que viven con viH-SIDA, una experiencia de Dios $^{1}$, a partir del ejercicio de su sexualidad? Como es sabido, este virus llega a la vida de una persona, en la gran mayoría de los casos, a través del ejercicio de la sexualidad ${ }^{2} \mathrm{y}$, a su vez, la práctica de la sexualidad suele estar cargada de prejuicios morales y éticos asociados a su confesión religiosa. Con todo, «es innegable que nuestra especie siente debilidad por el sexo» ${ }^{3} \mathrm{y}$ es imposible detener el ejercicio de la sexualidad sin importar los juicios o prejuicios que la determinan. No obstante, cuando el paciente (hombre o mujer) se entera de que es seropositivo/va, la pregunta recurrente suele ser, ¿̇por qué Dios me castiga de esta manera? Es el grito con que se confronta a Dios y a sí mismos/as. Para algunos constituye una prueba de Dios. Lo ven como un modo que Dios tiene de probar su

El concepto experiencia de Dios se asume como una vivencia posible y necesaria en la vida cotidiana de las personas, fundamentamos la experiencia a partir de los trabajos realizados por Raimundo Panikkar, La experiencia de Dios (Madrid: PPC, 1994), 34; Leonardo Boff, La experiencia de Dios, (Bogotá, Confederación Latinoamericana de Religiosos - CLAR, 1983), 4-11; Andrés Torres Queiruga, «La Experiencia de Dios, posibilidad, estructura, verificabilidad», Revista Pensamiento 211, Vol. 55 (1999) y Maestro Eckhart, Obras Alemanas. Tratados y sermones (Barcelona: EDHASA, 1983), 159-218. La sexualidad se entiende como un elemento constitutivo de la realidad humana y que se objetiva como vehículo comunicativo de la más alta eficiencia en la configuración de las relaciones interpersonales. Desde una perspectiva teológica se la entiende como el sello de Dios en la estructura misma de la naturaleza humana. Fundamentamos esta categoría a partir de los trabajos de Casimiro Bodelón Sánchez, Sexualidad y moral católica 7-8, Consultada en marzo 29, 2017. http:// bloc.mabosch.info/wpcontent/uploads/2012/07/4.2.5.5\%20SEXUALIDAD\%20Y\%20MORAL\%20 CAT\%C3\%93LICA\%20.Casimiro\%20Bodel\%C3\%B3n.pdf. Alberto Múnera, La sexualidad desde la Iglesia Católica (Bogotá: Pontificia Universidad Javeriana, 2006), 12-21. Michel Foucault, Historia de la sexualidad (México: Siglo xxi Editores, 2009), 93-11 y Marciano Vidal, Perspectivas de ética moral cristiana (Madrid: Tecnos, 1991), 25-40.

3 Cacilda Jethá y Christopher Ryan, En el principio era el sexo. Los orígenes de la sexualidad moderna. Cómo nos emparejamos y por qué nos separamos (México: Paidós, 2010), 19. 
fe. Otros lo interpretan como una oportunidad que Dios les concede para ser mejor persona: «Gracias al viH hoy soy mejor ser humano», son las palabras de un paciente que ha lidiado con el virus desde hace 25 años. Del mismo modo, quienes militan en el ateísmo, creen que la «ley de la compensación» ${ }^{4}$ los ha puesto en el lugar en el que están ahora.

De estos distintos modos de interpretar religiosamente la presencia del VIH-SIDA en la propia vida, se derivan algunas cuestiones que bien pueden ayudar a avanzar en la comprensión de la experiencia de Dios en personas que viven con viH-SIDA żquién es Dios en la vida de estas personas? ¿ ¿́cómo se manifiesta? Por la investigación sobre «la teología de salud» se sabe que la salvación de Dios «acontece en la historia, pero también en medio de sus ambigüedades y experiencias dolorosas, y penetra en la biografía de los hombres, no solamente en la historia del pueblo. La salvación se revela de modo especial allí donde la vida se ve amenazada, en aquellos que llevan en su misma carne los signos del mal y sienten obstaculizado en lo más profundo su deseo de vivir, y vivir en plenitud $»^{5}$. En palabras de Geraldo De Mori, «nada de lo que forma parte de la realidad finita, mundana y humana es extraño o extranjero a Dios» ${ }^{6}$.

No cabe duda de que la presencia del viH-SidA en la vida de una persona constituye un verdadero «punto de inflexión» ${ }^{7}$ que marca un antes y un después radical en la historia personal de un individuo, por

Según este modo de pensar, «la ley de compensación, se entiende como todo acto tiene en sí mismo su propia retribución. Toda acción, su reacción semejante». Giuseppe Isgró, «Ley de compensación noviembre de 2011», en Leyes del éxito (Blog), consultada en junio 10, 2016, http://leyescosmicasdelexito.blogspot.com.co/2011/11/ley-de-compensacion.html.

$5 \quad$ Francisco Álvarez, Teología de la salud 9 (Madrid: PPC, 2013).

6 Gerardo De Mori, «Una lectura teológica de la realidad. ¿̇ cuáles nuevos saberes recurrir o con qué saberes contar?», Teología y Vida 3, Vol. 53 (2012): 281-306.

7 La expresión punto de inflexión o su equivalente en inglés turning point se refiere a un punto de no retorno que puede adquirir una realidad social o la vida de una persona por influjo de un factor externo o como consecuencia de una acción específica de la persona. «La expresión punto de inflexión también hace referencia a los "giros inesperados que da una situación», cambios de sentido que pueden ir en una dirección y luego en otra, incluso girar $180^{\circ}$, y que pueden tener como particularidad que, si siguen un sentido, este puede volverse completamente al revés, y empezar de cero», Diego Gómez Ojeda, Punto de Inflexión. Expresión y significado, consultada en marzo 29, 2017, http:// diegogomezojeda.blogspot.com/2010/07/punto-de-inflexion-expresion-y.html. 
lo tanto, también cabe preguntarse si realmente, el VIH-SIDA, puede constituirse en objeto de redención para una persona.

Como tal, la relevancia teológica del problema es evidente y, máxime si se tiene en cuenta que no son pocos los seres humanos que hoy, en diferentes partes del mundo, enfrentan el problema del VIH-SIDA. Según el Ministerio de Salud y Protección Social para el 2012, solo "en Colombia se diagnostican 4200 casos nuevos cada año» ${ }^{8}$. En el 2016, el Instituto Nacional de vigilancia en salud pública (Sivigilia), «reportó 296 casos de VIH/SIDA en la última semana de noviembre de 2016 con 208 reportados de manera tardía que a comparación de la misma semana del año anterior se notificaron 216» ${ }^{9}$. El diario El Tiempo hace un reporte internacional: «Cerca de 7.500 mujeres jóvenes contrajeron el $\underline{\mathrm{VIH}}$ cada semana durante 2015, lo que les convierte en el grupo más vulnerable frente al sida, especialmente en África Subsahariana, una de las regiones más afectadas por la epidemia ${ }^{10}$. Como podemos ver en el mundo el panorama es desalentador, «la Organización Mundial de la Salud (OMS) calcula que el número de enfermos con VIH SIDA en el mundo es de 34 millones, de los cuales 30 millones son adultos y 3.4 millones son menores de 15 años. La oms estima que anualmente mueren 1.8 millones de personas por la enfermedad $»^{11}$.

Para la construcción del conocimiento teológico que pretendemos exponer en este artículo, por tratarse un problema existencial, no especulativo, en el que entran en juego los anhelos más profundos del ser humano, fue preciso prescindir de los métodos clásicos de

«Este es el panorama del VIH / sidA en Colombia», Revista Semana (Abril 2012), sección vida moderna, consultada en junio 5, 2016, www.semana.com/vida-moderna/articulo/este-es-el-panorama-delvih-sida-en-colombia/256926-3.

9 «Cifras del vin en Colombia en el Día Mundial de Lucha contra el Sida», Opinión y salud.com, revista digital, consultada en mayo 15, 2017, www.opinionysalud.com/cifras-del-vih-colombia-diamundial-lucha-sida/.

10 El Tiempo.com, consultada en mayo 15, 2017, www.eltiempo.com/vida/salud/cifras-de-vihen-2016-41230.

11 «Este es el panorama del vih / sida en Colombia». 
investigación teológica y hacer uso del método Investigación Acción Participativa (IAP).

Si bien es cierto, este método es propio de las ciencias sociales, en su configuración epistemológica, permite que tanto investigadores como investigados tomen conciencia de su realidad vital y, al hacerlo, puedan constituirse en seres humanos conscientes de su grandeza y de sus limitaciones, hacer uso de su libertad y poner en escena el ejercicio de sus convicciones, sus creencias y sus valores fundamentales. Esto, al fin de cuentas, es lo que busca todo conocimiento teológico trenzado con la vida cotidiana ${ }^{12}$ de las personas. Cabe anotar que el conocimiento en la vida cotidiana «se organiza alrededor del aquí de mi cuerpo y el ahora de mi presente. Este aquí y ahora es el foco de la atención que presto a la realidad de la vida cotidiana. Lo que aquí y ahora se me presenta en la vida cotidiana es la realidad de mi conciencia» ${ }^{13}$. Por lo tanto, el conocimiento parte de la experiencia vital de las personas que padecen en su propio cuerpo el impacto, la percepción de un Dios que hace parte de sus vidas y de las decisiones que fueron configurando su historia personal.

Como es sabido, la IAP parte de la premisa según la cual individual y colectivamente los seres humanos somos forjadores de nuestro propio destino; participamos en la creación de nuestro mundo vital como sujetos que sentimos, pensamos y actuamos ${ }^{14}$. Así, en este método, la «actividad intelectual» o producción del conocimiento, según Lewin Kurt, consiste en «otorgar poder a la gente para que pueda asumir acciones eficaces hacia el mejoramiento de sus

12 Para profundizar en este aspecto autores como Nelson Mafla Terán, Función de la religión en la vida de las víctimas del desplazamiento forzado en Colombia (Madrid: Universidad Complutense de Madrid, 2012), 169.

13 Peter Berger y Thomas Luckmann, La construcción social de la realidad (Buenos Aires: Amorrortu, 1986), 36-52.

14 Kurt Lewin, et al. «Investigación acción participativa. Inicios y desarrollos», en La Investigación Acción Participativa, inicios y desarrollos, comp. María Cristina Salazar Compiladora, 135-174 (Bogotá: Universidad Nacional de Colombia, 2011), 137. 
condiciones de vida» ${ }^{15}$. Posibilita que la gente "se cuestione sobre sus condiciones y busque mejores medios de actuar para su bienestar y el de su comunidad» ${ }^{16}$. Por otra parte, el método admite que las personas se involucren directa y creativamente en la investigación, puedan ver más claramente «la relación entre el conocimiento que se requiere para una mejor vida y lo que hay que hacer para lograrlo; el conocimiento se convierte en un elemento crucial que permite a la gente capacitarse y tener la posibilidad de decir cómo le gustaría que fuera su mundo y cómo dirigirlo» ${ }^{17}$.

De este modo, cuando nos hacemos las preguntas, ¿qué representación de Dios tienen los pacientes que viven con VIH? ¿Cómo viven su sexualidad a partir de la representación que han configurado de Dios? ¿ En qué momento el vir deja de ser un castigo o una maldición y pasa a convertirse en objeto de emancipación y punto de arranque para ser mejor ser humano? ¿̇Teológicamente hablando, el vir puede constituirse en objeto de redención para una persona?

Como se puede advertir, estamos ante una problemática de orden social, pero también ante un problema de orden teológicovital $^{18}$ que atañe a la vida concreta de los pacientes. Como problema, independientemente de que sea teológico o de orden social, implica el conocimiento y el uso del mismo en razón de una vida mejor del ser humano. Así las cosas, lo consideramos válido para la construcción del dato y la consecuente elaboración del conocimiento teológico. «En la IAP el camino que conduce de la generación de conocimiento a la utilización del mismo es directo, ya que los mismos actores se encuentran involucrados en ambas actividades [...]. La IAP reestructura esta relación entre conocer y hacer, y pone en manos

15 Kurt Lewin, et al. «Investigación acción participativa. Inicios y desarrollos», 137.

16 Kurt Lewin, et al. «Investigación acción participativa. Inicios y desarrollos», 137.

17 Kurt Lewin, et al. «Investigación acción participativa. Inicios y desarrollos», 137.

18 El problema del VIH como asunto que atañe a la teología, no es primicia de este escrito, la Iglesia Sueca Luterana, cuestionada por la presencia del VIH en África, en 2013, se hizo esta pregunta: «ટ̇cómo vamos a hacer teología mientras perdura la pandemia del VIH?», Valburga Schmiedt Streeck, org., Teología y VIH y Sida en América Latina (San Leopoldo: Conselho Editorial, 2013), 11. 
de la gente funciones tanto de producción como de utilización del conocimiento» ${ }^{19}$.

Estos presupuestos metodológico-epistemológicos tienen asidero en el fundamento teológico según el cual el ser humano puede acceder al conocimiento de Dios como experiencia en la propia historia personal y desde allí configurar una espiritualidad específica, es decir, un modo concreto de vivir según el espíritu que lo habita. Esto es asumir acciones eficaces hacia el mejoramiento de sus condiciones de vida.

Para ello nos fundamentamos en las investigaciones de Karl Rahner con respecto al «conocimiento de Dios» ${ }^{20}$, en la investigación de Gustavo Baena sobre Fenomenología de la revelación ${ }^{21}$ y sobre ¿Qué es la espiritualidad? ${ }^{22}$. En esta misma línea, nos apoyamos en Las fuentes de la espiritualidad ${ }^{23}$ y El arte del consuelo. Lo que sienta bien al cuerpo y al alma ${ }^{24}$ de Anselm Grün, así como la investigación de Juan Diego García Valencia sobre las Transformaciones de vida a partir de una relación personal con Dios ${ }^{25}$.

Según Rahner, «el ser humano, gracias a estructuras apriorísticas y a estructuras de apertura fundamental, puede acceder a la revelación de Dios que se le muestra como Absoluto. El sujeto humano es fundamentalmente pura apertura para todo en absoluto, para el ser en general ${ }^{26}$. Obviamente, no se trata de un conocimiento temático, ni representativo de la realidad de Dios, como lo dice el mismo Rahner. Se trata de un conocimiento enmarcado en la experiencia subjetiva

19 Valburga Schmiedt Streeck, org., Teología y viH y Sida en América Latina, 141.

20 Karl Rahner, Curso fundamental sobre la fe. Introducción al concepto de cristianismo (Madrid: Herder, 2012), 75-95.

21 Gustavo Baena, Fenomenología de la Revelación. Teología de la Biblia y Hermenéutica (Madrid: Verbo Divino, 2011), 161-185.

22 Gustavo Baena, ¿̇ué es la espiritualidad?, 2013, consultada en marzo 29, 2017, www.youtube.com/ watch? $\mathrm{v}=\mathrm{g} 8 \mathrm{mdFFZaBdk}$.

23 Anselm Grün, Las fuentes de la espiritualidad (Madrid: Verbo Divino, 2013), 55-79.

24 Anselm Grün, El arte del consuelo: Lo que sienta bien al cuerpo y al alma, Vol 315 (Santander: Sal Terrae, 2013), 21-29.

25 Juan Diego García Valencia, Transformaciones de vida a partir de una relación personal con Dios (Bogotá: Pontificia Universidad Javeriana, 2014).

26 Karl Rahner, Curso fundamental sobre la fe, 37. 
y anónima del sujeto. Según Rahner, «la experiencia trascendental sucede en la conciencia concomitante del sujeto cognoscente, la cual es subjetiva, no temática, está dada en todo acto espiritual del conocimiento y es necesaria e insuprimible, y su carácter ilimitado, abierto a la amplitud sin fin de toda realidad posible ${ }^{27}$.

En la misma línea, Gustavo Baena valiéndose del método trascendental de Rahner, considera que el ser humano es capaz de captar a Dios que se revela en la propia interioridad como experiencia, no como conocimiento deductivo-demostrativo. Dios sale al encuentro del viviente, toma la iniciativa de acercase y hacerse accesible. Dice Baena, «quedaríamos a ciegas con relación a lo que Dios es, a no ser que Dios mismo tome la iniciativa de acercarse y hacerse accesible hasta el punto de hacerse sentir por el ser humano; pero ello es obra de la pura gratuidad de Dios y no obra de un posible acercamiento nuestro por parte de nuestra razón ${ }^{28}$. ¿ Cómo revela Dios su propia intimidad? ${ }^{29}$. Dios se revela en la propia intimidad humana aconteciendo en él, creándolo desde dentro. En esta misma línea de pensamiento, la Constitución Dogmática Dei Verbum, se refiere a la revelación como el acontecimiento en el cual Dios mismo ha querido revelarse a hombres y mujeres.

Dispuso Dios en su sabiduría revelarse a Sí mismo y dar a conocer el misterio de su voluntad, mediante el cual los hombres [y mujeres], por medio de Cristo, Verbo encarnado, tienen acceso al Padre en el Espíritu Santo y se hacen consortes de la naturaleza divina. En consecuencia, por esta revelación, Dios invisible habla a los hombres como amigos, movido por su gran amor y mora con ellos, para invitarlos a la comunicación consigo y recibirlos en su compañía. ${ }^{30}$

Ahora bien, ¿qué tipo de ser humano puede oír y captar este tipo de mensaje? Se trata de alguien situado en la realidad de su

\footnotetext{
27 Karl Rahner, Curso fundamental sobre la fe, 38.

28 Gustavo Baena. ¿Qué es la espiritualidad?

29 Gustavo Baena, Fenomenología de la revelación, 161-225.

30 «Constitución Dogmática Dei Verbum», en Concilio Vaticano II, Documentos Completos (Roma: Vaticano, 1965), No. 2, consultada en marzo 29, 2017, www.vatican.va/archive/hist_councils/ii vatican_council/documents/vat-ii_const_19651118_dei-verbum_sp.html
} 
existencia y abierto a la trascendencia. Un ser humano que «mira a su interior, mira retrospectivamente a su pasado y contempla su entorno ${ }^{31}$ para mejorarlo. Un ser humano que se sabe amenazado por la culpa y, con frecuencia, entra en conflicto existencial consigo mismo ante la vacuidad o el impacto de sus acciones.

\section{Caminando con los pacientes}

Con estos presupuestos se configuró el proceso de investigación. A quienes aceptaron la invitación, se les presentó en detalle la propuesta, se determinaron las problemáticas que enfrentan como pacientes que viven con viH. Afloraron problemas de toda índole: religiosos, económicos, familiares, problemas sociales como el fenómeno de estigmatización, entre otros. Sin embargo, con la ayuda de los investigadores, la población finalmente se decantó por el tema de la experiencia de Dios en relación con la sexualidad y la corporeidad y así se pasó a la recolección de los datos y la construcción de conocimiento, proceso en el cual estuvieron involucrados pacientes e investigadores en la dinámica que estipula la IAP. Con el fin de propiciar el trabajo colaborativo entre pacientes e investigadores se optó por el taller como medio de participación. La realización de estos talleres tuvo dos objetivos: uno formativo y otro investigativo. En lo formativo, se hizo una aproximación teórica al tema de la sexualidad; en lo investigativo se buscaron escenarios para observar, determinar y debatir las principales dificultades que enfrenta un paciente que vive con viH en relación con su sexualidad de cara Dios. El procedimiento consistió en que pacientes e investigadores, a través de la escritura, la expresión artística como la pintura, el manejo de plastilina y la realización de mandalas, pudieran expresar sus vivencias relacionadas con su sexualidad y su experiencia de Dios. De este modo exteriorizaron vivencias, recuerdos, miedos, necesidades, anhelos, valores y predisposiciones ante el intrincado mundo de su propia sexualidad de cara a la divinidad.

31 Gustavo Baena, Fenomenología de la revelación, 46. 
En segunda instancia, con la idea de ahondar en la problemática detectada en los talleres participativos se realizaron entrevistas semiestructuradas con los pacientes, orientadas a indagar la relación Dios y sexualidad. De este modo se involucraron pacientes e investigadores en una reflexión participante y transformadora con respecto a la sexualidad de cara Dios, y en la comprensión de que somos seres sexuados, porque la sexualidad como lo dice Vidal «no se reduce al ámbito de los impulsos genitales, ni mucho menos al mero acto sexual» ${ }^{32}$.

\section{1 ¿Quiénes son? su caracterización ${ }^{33}$}

Con el fin de construir una caracterización de la población, se realizó una encuesta, que se aplicó a 167 pacientes, con la intención de establecer las características de la población con respecto al credo religioso, las representaciones de Dios, la acción de Dios en su vida, la percepción que tiene él mismo de su propio cuerpo, la vivencia de la sexualidad antes y después del diagnóstico, y las formas de cuidado asumidas por el paciente.

Compartimos aquí los resultados que permiten acercarnos a la configuración del perfil religioso de las personas que viven con ViH.

\section{- El credo que profesan:}

Con la entrevista se pudo determinar, que el $75 \%$ de los pacientes se ubican en un determinado credo religioso: cristiano católico, cristiano evangélico, Wiccano y Yoruba. Un 14\% dice no pertenecer a ningún credo religioso y el $12 \%$ no sabe o no responde la pregunta. Cabe resaltar que el 73\% de la población toma su inspiración religiosa del cristianismo.

\section{- Su representación de Dios:}

La encuesta permitió caracterizar la representación que tienen los pacientes de Dios. Es interesante resaltar que pese a lo doloroso 
que representa vivir con el viH, la imagen que tienen de Dios es altamente positiva.

Para el 43\% de la población, Dios se muestra como compasivo y misericordioso; seguido del 15\% que considera a Dios como padre y madre. Para otro 16\% Dios es amigo, compañero y protector, amor, ser supremo y creador. Un $2 \%$ ve en Dios a alguien que enseña y orienta. Únicamente para el $2 \%$ de la población Dios aparece como alguien que juzga y que castiga.

\section{- La acción de Dios en su vida:}

De la representación que tienen de Dios, se pudo derivar la acción que Él desempeña en sus vidas. Para el 28\% de la población, Dios otorga la fe que a su vez se constituye en aliciente importante para vivir; constituye el apoyo y la fortaleza para seguir adelante. También se puede destacar que para el 23\% de la población, de la imagen de un Dios misericordioso y compasivo, de un Dios padre y madre, amigo, compañero y protector se deriva un modo específico de acción del paciente, pues Dios hace que la persona asuma un comportamiento responsable consigo mismo y con los demás.

Es interesante que de esta manera de comprender a Dios se derive el hecho que para el $22 \%$ de la población, Dios es el encargado de otorgarle sentido a su vida.

$\mathrm{Fe}$, responsabilidad y sentido: tres categorías sumamente relevantes derivadas de una representación de Dios específica y que a la postre se constituyen en conocimiento teológico que emerge de la vida cotidiana de personas que a diario se enfrentan con la presencia del viH en sus vidas.

\subsection{Su vivencia de la sexualidad}

A partir de esta experiencia de Dios en la vida de los pacientes se deriva una vivencia de la sexualidad con unos rasgos diferenciados: el $10 \%$ de la población indicando que su vida sexual no tiene por qué cambiar con el advenimiento del viH, el 14\% de los pacientes se consideran menos promiscuos y un $31 \%$ dicen ser más responsables. 
Cabe resaltar la existencia del 10\% de la población indicando que su vida sexual no tiene por qué cambiar con el advenimiento del viH. El dato es relevante, pues en este $10 \%$ posiblemente están los pacientes que se resisten a un cambio en sus prácticas sexuales y siguen practicando la sexualidad sin ningún tipo de cuidado y dispuestos a contagiar a otras personas. Este dato, es el resultado de cruzar información proveniente de la encuesta y de la información derivada de las entrevistas y los talleres. En estos escenarios aparecieron argumentos como: "yo no me tengo que cuidar, el que se tiene que cuidar es el otro». «Si a mí me la hicieron yo se la tengo que hacer a alguien». "Yo no tengo por qué cambiar mi vida sexual, yo no soy responsable de los demás».

En este tipo de información se ve la diferencia que marca, en la acción de los pacientes, el hecho de creer o no creer en Dios. Es muy probable que quienes sinceramente creen y enmarcan su vida desde una perspectiva de fe, responsabilidad y sentido, asumen una actitud diferente, de cuidado de sí mismos y del otro. Incluso la misma sexualidad adquiere una dimensión teológica (amor, encuentro, entrega) en contraposición a una práctica de la sexualidad anclada en lo estrictamente fisiológico.

\section{Acercándonos a su autoconocimiento ${ }^{34}$}

En el camino de una investigación de este tipo es muy importante la construcción del conocimiento a partir de la autoimagen y el reconocimiento que cada uno haga de su experiencia y de su situación. Tal es el sentido que tiene trabajar con la mediación del taller. Por ello se le otorgó todo el reconocimiento y la validez a la palabra y la experiencia vital de cada uno y del otro; en este caso, la palabra y la experiencia vital del paciente que vive con viH.

Así, el otro (el paciente) no fue solo un objeto de observación, fue sobre todo un sujeto que habló y a quien se escuchó con reverencia en

34 Este apartado presenta el conocimiento construido a través de los talleres. 
su grandeza y opacidad. De parte de los investigadores se pusieron los medios para que ellos (los pacientes) expresaran el conocimiento que tienen de sí mismos y de Dios en razón de su sexualidad. Se partió de la premisa básica de que el paciente, como sujeto en posesión de un lenguaje que le permite objetivar su mundo interior, está en capacidad de exponer su mundo espiritual con acierto y sinceridad. De este modo, los investigadores asumimos el rol de mediadores, de facilitadores de la puesta en marcha de un proceso sistemático de información capaz de recopilar, entre la población sujeto de la investigación, un conocimiento de Dios ya elaborado pero disperso. Se trata de un conocimiento de Dios acrisolado en el transcurso de años de adversidad, provocada por el hecho de llevar consigo VIH-SIDA que ha significado estigmatización, rechazo y como consecuencia de ello dolor que hace brotar una lágrima cada vez que el paciente escarba en sus recuerdos de cómo fue el día que le dijeron que tenía VIH. Por tanto, ello nos pone frente a un conocimiento digno de todo respeto y admiración.

Así, los talleres fueron la mediación para aproximarse a la comprensión de la sexualidad desde la realidad de la vida cotidiana ${ }^{35}$. También, fueron el medio para acceder a las dificultades que enfrenta el paciente con respecto a la vivencia de la sexualidad de cara a Dios.

\subsection{Reconociendo el lenguaje}

«Su nombre me suena» fue la designación dada a un taller para acceder al léxico sexual del paciente. Se les pidió que en grupos de tres personas expusieran en una cartelera los nombres con los cuales

35 En este artículo, «la realidad de la vida cotidiana, se entiende como el conjunto de prácticas, usos y costumbres de la vida diaria de una persona en particular o de una comunidad humana en general. Corresponde a la forma real en que se viven los valores, las creencias, las aspiraciones y se suplen las necesidades. Incumbe a vivencias diarias, repletas de significados, intereses y estrategias. Estas últimas corresponden a la serie de comportamientos que permiten crear una red personal de caminos por los cuales, el sujeto, diariamente transita y construye relaciones sociales. La vida cotidiana es la esencia de lo que está encima y en la raíz de las costumbres, usos, comportamientos y necesidades de los sujetos (Laverde, 2006). En tanto esencia del mundo social del sujeto es coherente y significativa». Nelson Mafla Terán, Función de la religión en la vida de las víctimas del desplazamiento forzado en Colombia, 169. 
suelen nombrar en la vida cotidiana a sus órganos sexuales y sus prácticas sexuales.

Llamó la atención que únicamente un grupo de trabajo se refirió a los genitales y las prácticas sexuales desde una perspectiva emocional y amorosa y los puso en un plano de cariño y de amor. En los demás grupos se pudo evidenciar, tanto en lo escrito como en los gestos y comentarios, que genitales y prácticas sexuales están asociados a una comprensión de la sexualidad desde la genitalidad, asociada al pasarlo bien, a lo sensitivo, el placer sexual por el placer. No se juzga este tipo de percepción de la sexualidad, solo se indica que los pacientes se mueven en este plano cuando se trata de la comprensión de su sexualidad. Lo que nos lleva a concluir con López Aspitarte que la «sexualidad requiere una educación para poderla vivir como expresión y lenguaje humano» ${ }^{36}$.

Al final del taller, con la participación de los investigadores, se llevó al grupo a reflexionar que más allá de una comprensión genital de la sexualidad, es obvio que la sexualidad humana no se puede agotar allí. De hecho, el ser humano es la única especie que practica sexo sin fines reproductivos, lo que indica que tenemos la capacidad de controlar y dar sentido a las prácticas sexuales. Si ello es así, ¿̇por qué no ubicar la sexualidad como práctica en un plano de compromiso y responsabilidad?

\subsection{Las dificultades: «sexualidad» y «Dios»}

Un segundo taller tuvo como objetivo determinar las dificultades que enfrenta un paciente con respecto a su sexualidad de cara a Dios. Se pudo conocer que la principal dificultad estriba en la formación sexual temprana que recibieron cuando niños/as, de parte de la familia, la escuela, la religión y el entorno social. Según los pacientes, estas instancias de socialización dan por hecho que el niño o la niña son heterosexuales $y$, en consecuencia, se les trata y

36 Eduardo López Azpitarte, Simbolismo de la sexualidad humana: criterios para una ética sexual (Santander: Sal Terrae, 2001), 36. 
se les educa en esa perspectiva. Por ejemplo, en los cuatro escenarios al chico/a se le motiva y hasta se le presiona, para sentir atracción por el sexo opuesto. De manera intencional o inconsciente, tanto amigos, escuela, familia y religión empiezan a hostigar al niño con comentarios como: si tiene novia, que tal chica/co es muy bonita/to; si es niño, el comentario suele ser que la vecina lo mira, que el tío a los 5 años ya tenía novia y, por tanto, es un «verraco». Si está en una fiesta, se le incita a cortejar a las chicas, etc. De este modo al niño/a se le va configurando su sentir sexual hacia las personas del otro sexo.

Para los pacientes protagonistas de este estudio las dificultades empezaron cuando comenzaron a sentirse atraídos por personas del mismo sexo. En efecto, en el contexto donde crecieron, sentirse atraído/a sexualmente por una persona del mismo sexo era pecado. De este modo, desde temprana edad, los pacientes comenzaron una lucha interior entre lo que sentían sexualmente por las personas del mismo sexo y lo que la familia, los amigos, la religión y la escuela esperaban de ellos.

En medio de esta lucha interior insostenible para un adolescente, vinieron las confesiones con sacerdotes y el acompañamiento espiritual con pastores para los no católicos. En muy pocos casos hubo confesiones con amigos. Quienes se confesaron con sacerdotes y tuvieron acompañamiento de pastores cristianos no católicos ratificaron que estaban en pecado y que debían corregir de inmediato ese tipo de prácticas. Al respecto indica un paciente, «cuando me confesé para hacer la primera comunión, el sacerdote me dijo que estaba en pecado mortal y que debía dejar de hacerlo y me mandó a rezar padrenuestros y avemarías».

Ante la angustia de no saber qué hacer, ni cómo controlar «esa fuerza invencible interior que carcome el espíritu, que quema la carne, que hace hervir la sangre y que nos arrastra hacia la homosexualidad ${ }^{37}$, alguien pensó en cortarse el pene, otros hicieron

37 Cornelio Buendía (nombre ficticio). Paciente que vive con viH-SIDA, hizo parte de las personas que participaron de los talleres (comunicación directa). 
la escaramuza de huir de la región o suicidarse, otros intentaron aplacar el deseo con la masturbación. Estos últimos entraron en un doble conflicto: por una parte, debían lidiar con el «pecado» de sentirse atraído por personas del mismo sexo y, por otra parte, debían combatir el «pecado mortal» de la masturbación.

Dice Arango ${ }^{38}$

Yo me masturbaba porque pensaba que la masturbación era pecado, pero más chiquito que el pecado de tener sexo con un hombre. Pero llegó un momento que no pude soportar más y me volví un pecador compulsivo. Ya no me importaba el infierno, ni los curas. No me importaba nada. Ahora veo que esta situación me hizo mucho daño, porque toda mi vida sexual ha sido una historia de pecado.

Quienes se confesaron con amigos no corrieron con mejor suerte. Terminaron siendo cuestionados y en algunos casos apartados de la amistad. Incluso, hubo un caso en el cual el sujeto terminó siendo violado por la persona a la que le comentó la situación.

Cabe apuntar que el Catecismo de la Iglesia Católica cataloga la masturbación lo mismo que la práctica de la homosexualidad como pecados graves. «Entre los pecados gravemente contrarios a la castidad se deben citar la masturbación, la fornicación, las actividades pornográficas y las prácticas homosexuales» ${ }^{39}$. En otro apartado del mismo catecismo se lee que «tanto el Magisterio de la Iglesia, de acuerdo con una tradición constante, como el sentido moral de los fieles, han afirmado sin ninguna duda que la masturbación es un acto intrínseco y gravemente desordenado» ${ }^{40}$. Ahora bien, el Magisterio de la Iglesia en la voz de papa Francisco, abre la discusión sobre el tema de la sexualidad y del amor de la pareja en términos de conocimiento corporal, sentimientos y afectos «Por algo será que un amor sin placer ni pasión no es suficiente para simbolizar la unión del corazón

\footnotetext{
38 Los nombres que se utilizan en este escrito son ficticios. Con ello se busca preservar el anonimato de quienes proporcionaron la información.

39 Catecismo de la Iglesia Católica (Vaticano: Editrice Vaticana, 1992), No 2396.

40 Catecismo de la Iglesia Católica, No. 2352.
} 
humano con Dios $»^{41}$ Lo que nos hace pensar que Francisco presenta una doctrina de misericordia y de aceptación de la dimensión corporal de la sexualidad más allá de los condicionamientos morales y las concepciones de pecado.

En relación con la exploración de la sexualidad, para la mujer la situación no es menos problemática. Carmenza manifiesta: «como mujer siempre me he cuestionado mi rol en la sociedad, ya que desde lo religioso las mujeres siempre hemos sido símbolo de pecado y por tal culpabilizadas. Ahora estoy alejada de lo religioso, pero con una espiritualidad fortalecida». Angélica indica que cuando su madre se enteró que le atraía sexualmente una compañera de la clase, le dio una paliza que sigue recordando hasta hoy, 25 años después.

A Juliana, hace 30 años la expulsaron del colegio cuando la «hermana rectora» se enteró de que era lesbiana; recuerda que les dijo a los papás «una naranja podrida corrompe a todas las demás». Juanita, cuando empezó a sentir «cosas» por su vecina no sabía qué hacer y con sus 15 años se acercó al pastor de su Iglesia, le comentó el caso. «Esto es obra del demonio», le manifestó en seguida, le hizo exorcismos y al ver que el mal persistía la expulsó de la Iglesia. Fue problemático, lo recuerda con resentimiento como si fuera ayer y han pasado 25 años. En este momento, después de un largo trayecto de reflexión personal y ayuda del sacerdote de su parroquia, ha podido perdonar. «En este momento hay personas que entienden mejor las cosas y le ayudan a uno», dice, mientras deja rodar una lágrima en su mejilla. «Si ya ser mujer es problemático en una sociedad machista como la colombiana, ¿̇cómo serán las cosas para nosotras las mujeres ahora que además de ser mujeres, vivimos con el viH?», es la pregunta que se hace Juanita. Andrea, por su parte, esculcando en sus recuerdos, advierte que abandonó su hogar cuando su familia se enteró que era lesbiana. No pudo soportar la discriminación de

41 SS Francisco, Exhortación apostólica postsinodal Amoris Laetitia (Roma: Vaticana, 2016), consultada en mayo 14, 2017, http://w2.vatican.va/content/francesco/es/apost_exhortations/documents/papafrancesco_esortazione-ap_20160319_amoris-laetitia.html. 
los suyos. Para sobrevivir tuvo que ejercer la prostitución y, ahí adquirió el vir. No es una novedad para una mujer en situación de vulnerabilidad, «para muchas mujeres del mundo, el último y único recurso de sobrevivencia está en prostituirse» ${ }^{42}$.

Independientemente de si es hombre o mujer, para algunos el mayor problema radica en no poder tener una pareja estable. Reconocen que en el mundo gay la fidelidad, en la mayoría de los casos, es prácticamente nula. Piensan que el amor puede transformar la vida, pero les cuesta mantener una pareja a través del tiempo.

Las dificultades que enfrenta un paciente que vive con viH después del diagnóstico son diferentes a las dificultades prediagnóstico. La principal dificultad radica en el deterioro del cuerpo. El testimonio que recoge esta situación es el de Gilberto.

Antes de la enfermedad tenía un cuerpo atractivo, las relaciones me caían como del cielo. Después de corto tiempo, por efecto de los medicamentos y las enfermedades asociadas al viH-SIDA, mi cuerpo se ve pálido, ya no soy el mismo, no tengo la misma fortaleza y se ha perdido por completo mi atractivo. Mi pelo se ve opaco, casi no tengo pelo. Antes del diagnóstico era fácil conseguir una relación afectiva pasajera (de una noche), ahora es complicado...Ahora salgo a la calle y nadie me determina. Las personas apenas se enteran que vivo con VIH-SIDA se alejan inmediatamente. Sufrí mucho, hasta ahora que entendí que el sexo no lo es todo en la vida. Por eso yo vine a este taller, porque quería aprender más sobre sexualidad. Le doy gracias a Dios que haya puesto en mi camino personas como ustedes que nos enseñaron que la sexualidad es compromiso y responsabilidad con uno mismo y con el otro. Entender esto, para mí ha sido como salvarme.

Para otra parte de la población, el problema radica en haber perdido la libertad. En este momento se sienten atados porque no pueden tener relaciones afectivas como antes. Ahora, por compromiso moral, cuando van a comenzar una relación, sienten que están en el deber de informar a la otra persona de ser portadores del VIH-SIDA; en el momento que lo hacen, las personas los abandonan. También 
están los pacientes que cayeron en depresión y no han podido salir de ella. Y están también quienes siguen peleando con Dios y con la vida por haberlos castigado de esa manera.

Como decíamos antes, para los pacientes el enterarse que tenían VIH significó un punto de inflexión en su historia personal. Perdieron familia, se quedaron solos, la salud se ve deteriorada, se complicaron las relaciones sociales. Algunos, por ejemplo, no soportan la idea de usar preservativo para las relaciones sexuales.

\subsection{Vivir con el viH-sidA en la presencia de Dios}

Con todo, al lado de estos pacientes están los que ven en el VIH-SIDA una bendición de Dios. Por el VIH-SIDA se sienten salvados, consideran que gracias a ella pudieron conocer otras personas maravillosas, encontrar el amor de su vida, volver a sentir la presencia de una familia. En medio de todo sienten la mano de Dios porque fue el medio que puso Dios en sus vidas para que pudieran vencer el orgullo, volverse personas tranquilas, amables y agradecidas con la vida. Antes no eran capaces de agradecer a Dios por nada, ahora agradecen por poder caminar, respirar. «Yo me volví como un niño que da gracias por todo a Dios. Gracias a el viH-SidA encontré a Dios. Este taller me ha ayudado a reforzar esta fe que tengo en Dios. Uno es firme en lo que cree, pero a veces hace falta que otros que le ayuden», indica uno de los pacientes.

Con el advenimiento del vir a la historia personal, sienten que están más cerca de Dios, han dejado de ser orgullosos. Para otros el VIH ha significado fortaleza, saber sostenerse en la adversidad. El VIH les ha ayudado a poner la vida en las manos de Dios. «Uno crece espiritualmente, hay un acercamiento a Dios, hay una búsqueda, a quien más se le pide es a Dios. Todos los días toca estar pegado de Dios».

Una vez han tomado conciencia de la situación, en la práctica de la sexualidad, la mayoría quieren vivir el valor del respeto y así mismo quieren que los demás también lo vivan. Le siguen la sinceridad y el 
cuidado. ¿Por qué el respeto? Según ellos el respeto permite «llegar con la persona hasta donde la persona permite llegar, sin obligarlo a nada. Respetar lo que el otro quiera hacer sin forzar nada». La sinceridad se refiere a informar que se es portador, aunque según los manuales de comportamiento no es obligación.

Más allá de las dificultades de orden corporal, los talleres también permitieron evidenciar cómo son los diálogos íntimos del paciente con Dios. En el caso de los hombres, cuando sintieron sus primeras inclinaciones a lo homosexual, su pregunta a Dios era: ¿ Por qué me gustan los hombres y no las mujeres? ¿Es pecado esto que hago?

Dice Armando:

por sentir la inclinación a los demás hombres comencé a conseguir una comunicación con Dios más frecuente. Siendo niño le preguntaba, por qué me gustan los hombres. Le pedía ayuda para que me quitara esos deseos, que me quitara esas inclinaciones de mi ser, eso estrechó mucho mi relación con Dios. Era muy frecuente la relación con Él. Eso hizo que fuera muy de iglesia, de confesión, de sentirme pecador. Pensaba que estaba en una situación de pecado, me sentía culpable de ser homosexual. Siempre he llevado esa cruz. Mi sexualidad estaba ligada a Dios porque era una sexualidad de negación. Me sentía pecador. Si hubiese sido heterosexual posiblemente jamás me habría acordado de Dios. Habría sido feliz.

\subsection{El camino del sufrimiento}

También los talleres permitieron constatar que los pacientes hombres se enamoran sinceramente de sus parejas, por eso cuando hay un rompimiento de la relación el dolor es grande. Armando en un diálogo con sus compañeros de grupo de trabajo indica que sus padres no eran afectuosos, «faltó una caricia, no hubo un beso, faltó mucho amor, en la búsqueda de ese amor se me ha pasado la vida». 


\section{¿Sientes que has encontrado ese amor?}

«Sí lo encontré, y le digo a Dios por qué me lo quitó, fue una época de la vida muy bonita, pero se acabó, no duró, se acabó, y de eso no me he recuperado».

\section{¿Qué le pasó a ese amor?}

«Duró 15 años. Fueron tres años bonitos y 10 años de sufrimiento y finalmente se fue. Me duele mucho hasta ahora». «El amor es como una planta que echó raíces en mi cabeza. Está ahí y no desaparece. No lo puedo arrancar. Quedé como el toro que marcan, es una marca que no se quita. El amor entre dos hombres cuando es verdadero es tremendamente poderoso, dos hombres son activos, son pasión. No me he podido sacar de la mente ese amor. Dios me lo quitó».

¿Qué le pides a Dios? «Que lo olvide, que me permita hacer una nueva vida».

\section{Compartiendo vida y conocimiento $^{43}$}

En el proceso de construcción de los datos, después de los talleres se pasó a la configuración de las entrevistas con los pacientes. Fueron 15 entrevistas realizadas en un ambiente tranquilo y de mutua confianza entre entrevistador y paciente, lo cual garantizó la apertura necesaria para exponer la información. En este ejercicio investigativo se pudo constar que el tema de la sexualidad de cara a Dios y la propia psicología del paciente es sumamente compleja y, por lo tanto, difícil de encajarla en una perspectiva lógico-deductiva. De ahí que, la narrativa se constituyó en el medio más apropiado para acceder a este universo llamado «Dios y sexualidad en la vida de pacientes que viven con VIH». Cada paciente es un multiuniverso diverso. De ahí que intentar exponer patrones o fórmulas de vida es una pretensión insensata. Por lo tanto, lo que se ofrece a continuación son vivencias, experiencias. Todo con la sola pretensión de sacar a flote lo que vive un paciente y que su vida sea un argumento inspirador para quienes puedan acceder a este tipo de literatura.

\footnotetext{
43 En este apartado se presenta el conocimiento construido a partir de las entrevistas.
} 
Las entrevistas permitieron acceder a dos tipos de información: una relacionada con las frustraciones que viven los pacientes por no poder llevar a cabo en su vida una sexualidad normal, y el otro tipo de información correspondiente a la función de Dios en la vida del paciente.

\subsection{Frustración y vida sexual}

A través de las entrevistas se pudo constatar que el estado físico determina prácticamente todo en la vida de la persona. Especialmente las emociones. Según el estado físico del paciente cambia su componente emocional. Cada paciente tiene su propia manera de enfrentar la adversidad. En el momento en que un paciente se entera de que tiene $\mathrm{VIH}$, su primera reacción es el rechazo al diagnóstico, negación del mismo, seguido esto de un bloqueo emocional donde la sexualidad se ve tan afectada que pierde su importancia.

Posterior a este momento, viene la etapa de la reflexión. Con el paso del tiempo, cuando los pacientes ven el deterioro o desgaste de su cuerpo, cambia de inmediato su universo emocional y junto con él sus relaciones familiares, sociales, laborales y hasta con Dios. Se pudo constatar que el viH-SIDA ocasiona impactos psicológicos y espirituales que dejan heridas y cicatrices profundas. Es esta situación la que logra un cambio profundo en sus emociones y los hace adoptar incluso, personalidades extrañas, distintas maneras de comportarse frente a sí mismo y los demás. Este dato es relevante por cuanto de estos cambios profundos van a depender tanto la forma en que acepten la presencia del vir en sus vidas como el manejo de su sexualidad de cara a Dios.

Una vez en la etapa de reflexión vienen preguntas como: ¿Cuánta vida tengo? ¿Qué voy a hacer? ¿Quién me contagió? ¿Es posible iniciar algún tratamiento? Todas estas preguntas vienen acompañadas de un rechazo por todo lo relacionado con el contacto sexual o acercamiento corporal. En esta etapa el paciente decide dejarse ayudar o enfrentar el problema solo. Quienes deciden buscar 
ayuda, emocionalmente se disponen a una relación positiva con Dios, con la sociedad y con la familia. Esto hace que algunos vean el VIH-SIDA como una bendición que los lleva a iniciar un cambio en su interioridad, el cual trae como resultado el mejoramiento del entorno y la sensación de volver a nacer. Es aquí donde el paciente siente el punto de inflexión en su historia personal. Emprenden un camino de búsqueda de sí mismo, de búsqueda de Dios; se aferran a la vida, a la familia, a la pareja buscando afecto, cariño, amor, respeto y compañía en el otro. La búsqueda del placer por el placer en el ejercicio de la sexualidad pasa a un segundo plano y se enfocan en la construcción de relaciones duraderas. Valoran la amistad, el respeto. Sienten que son personas nuevas.

Con todo, se enfrentan a frustraciones significativas relacionadas con la funcionalidad de la sexualidad en la vida pues en muchos casos, la presencia del viH viene acompañada de incapacidad para procrear; no por incapacidad física, sino por sentirse rechazados, discriminados, juzgados, señalados y abandonados; no se sienten con la plena capacidad de dar vida. Con ello, viene la frustración más grande: no poder ser padres o madres. La situación adquiere un matiz mucho más profundo cuando el hecho es confrontado con el mandato bíblico «Creó, pues, Dios al ser humano a imagen suya, a imagen de Dios le creó, macho y hembra los creó. Y bendíjolos Dios, y díjoles Dios: "Sed fecundos y multiplicaos"» (Génesis, 1, 27-28a).

Es el caso de Cristóbal, un paciente de 22 años, quien dice que en su condición no se arriesga a concebir un hijo por miedo a que sea infectado. Que no se atreve a causar tal daño a un bebé que no pide que lo traigan a sufrir lo que él está sufriendo. Para Cristóbal, la frustración va más lejos pues es hijo único y su madre le dice que quiere nietos y, él no sabe cómo decirle lo que le está sucediendo.

La segunda frustración tiene que ver con el ejercicio normal de la sexualidad, con la función de la sexualidad orientada a la satisfacción del deseo sexual. Un paciente que vive con viH y se rige por códigos morales, se enfrenta al temor permanente de contagiar a 
otros. Se cohíben de cualquier asomo de una relación. Con ello evitan ser responsables de transmisión del virus, pero también evitan ser objeto de cualquier asomo de rechazo o discriminación. La situación desemboca en situaciones graves como el caso de Cristóbal que evita a toda costa una relación y para satisfacer su deseo sexual recurre a la masturbación. Según él, prefiere masturbarse en la ducha por el miedo a contagiar a alguien y evita relacionarse abiertamente. No nos corresponde aquí entrar en el ámbito psicológico, pero este tipo de anomalías en el manejo de la sexualidad, con toda seguridad es devastador por todo el desequilibrio emocional que ello implica.

En contraposición de la actitud de Cristóbal, están los pacientes que asumen una postura de venganza ante la sociedad y cada día se levantan con la única intención de salir a contagiar a cuantas personas se crucen por el camino. «Yo no tengo responsabilidad con nadie, a mí me contagiaron y yo me tengo que vengar haciendo lo mismo», son las palabras de Jorge. Otra expresión común en estas personas es: «quienes se deben cuidar son los demás», por lo tanto, ellos piensan que no tiene ninguna responsabilidad con los otros. «Si el otro da papaya que lleve».

En el tercer grupo están los pacientes que adoptan una conducta responsable frente a sí mismos y frente a los demás. Una vez que se enteran de que son seropositivos, rápidamente se preocupan por buscar acompañamiento. Con ello se abren al desarrollo espiritual encontrando en Dios su refugio, mejoran su relación familiar y social e intentan llevar una vida sexual normal. Es el caso de Tomás, un paciente que hace 25 años vive con el viH y ha logrado integrarse a su familia, a grupos de apoyo donde le han ayudado a fortalecerse y conocer más acerca del viH. En este momento lleva una vida sexual normal con su pareja, los dos se cuidan y viven bien.

Otra de las funciones de la sexualidad tiene que ver con la unión de la pareja humana. Ante esta función de la sexualidad algunos pacientes manifiestan gran frustración al sentir la dificultad de poderse casar y formar una familia. Todo el conflicto estriba en el 
miedo al rechazo, a no ser aceptados por parte de su pareja. Con ello desaparece en su vida, la otra de las funciones de la sexualidad que es la de brindar seguridad y esperanza a la persona cuando se es capaz de consolidar relaciones duraderas. La mayoría de los pacientes sienten la necesidad de estar acompañados por otra persona a nivel de pareja, tener a alguien que sea soporte afectivo, acicate emocional. Pero, el miedo, nuevamente hace que no lo puedan lograr y se vean enfrentados a la soledad y la frustración.

A manera de cierre se puede decir que si los pacientes se sienten frustrados en estas cuatro funciones de la sexualidad y permiten que se apoderen de ellos los sentimientos de miedo y desconfianza, sus emociones se verán afectadas considerablemente y serán presa fácil de la tristeza, la desolación y la soledad. Esto, unido al miedo infundido por los médicos y personas que hablan de muertes ocasionadas por el virus, es el caldo de cultivo perfecto para perder la autoestima, la fe en sí mismos y la fe en los demás. Este es el principal motivo de suicidio o abandono del tratamiento.

\subsection{Manifestación de Dios en la experiencia con el VIH-SIDA}

La construcción de los datos en relación con este aspecto se realizó alrededor de la pregunta, żexiste alguna relación entre Dios y tu experiencia con el ViH? ¿Cómo se ha manifestado Dios en relación con tu experiencia con el VIH?

Como se indicó antes las entrevistas se hicieron a 15 pacientes. Con la idea de recoger la información en su totalidad a continuación se describen los datos de una muestra de 5 pacientes ${ }^{44}$. Para garantizar el anonimato del paciente aparecerán como paciente 1, paciente 2, paciente 3 , etc.

Paciente 1 «Digo que Dios tiene un vínculo con el viH, porque cuando uno siente que se muere, que se hunde, está Dios de alguna

44 Las respuestas se consignaron con exactitud. Únicamente se incluyeron signos de puntuación y detalles de transcripción necesarios para la comprensión del sentido de las mismas. 
manera impidiendo que mueras y dándote una nueva oportunidad de vida y de poder compartir más tiempo con mis hijos. La verdad si estoy viva es porque Dios así lo quiere».

Paciente 2 «No creo que haya un vínculo entre Dios y el ViH, porque esto es completamente mi irresponsabilidad, por eso me pasó, por irresponsable. No sé si todos tengamos un camino trazado ya, o planificado por alguien, pero yo pienso que esta situación de enfermedad y de angustia es producto de lo que has hecho, que uno mismo se lo ha buscado. Quizá no porque yo haya dicho me voy a infectar con VIH, no, para nada, sino que confiamos en alguien y resulta que no era lo que esperaba y me hizo un daño irreversible. No creo que sea culpa de Dios o que él crea que a mí me toca vivir esto. Cada quien es libre en sus acciones».

Paciente 3 «La iglesia no tiene por qué saber de nuestra condición, y la verdad, no es la discriminación de la religión, sino de la gente que asiste a los templos».

Paciente 4 «No hay vínculo entre la experiencia del viH y Dios, yo me contagié porque fui irresponsable, Dios no tiene que ver nada con esto. Dios no me llevó a esto, no le echo la culpa ni a Dios ni a la persona que me contagió, es mi responsabilidad totalmente».

Paciente 5 «Creo que hay vínculo entre Dios y el viH o cualquier otra enfermedad. Dios busca su forma, sus medios para mostrar que estamos obrando mal. Dios no es un dios castigador, no tomo la enfermedad como un castigo. Estoy tomando la enfermedad como una forma de cambio, no quise abandonar los caminos pecaminosos a las buenas, pues los abandoné a las malas. El viH me acercó mucho más a Dios».

¿Por qué los pacientes asumen está manera de ver la adversidad de cara a Dios? ¿Puede el viH constituirse en objeto de redención? De ser así, ¿̇ónde está la línea divisoria entre lo salvífico y lo patológico? La respuesta está en la percepción que el paciente tiene de Dios. Esto es, de sus características y del modo de manifestarse en la 
historia de cada uno. Cabe apuntar que aquí estamos ante uno de los postulados claves de la teología fundamental cristiana: Dios se revela en la historia de la humanidad.

La teología cristiana, en cuanto logos/palabra/discurso sobre Dios -que es un Dios que habla a los humanos-, no es un saber esotérico -reservado a una élite de iniciados-, o totalmente trascendente, sin nada que ver con la realidad. Al contrario el Dios cristiano se revela en la historia y a la historia con sus «angustias, alegrías, sufrimientos y esperanzas $»^{45} \mathrm{y}$, por el misterio de la encarnación del Logos/Palabra/Hijo, asume las vicisitudes, posibilidades y límites de esta misma historia, acompañándola, dándole sentido, salvándola. Por lo tanto, nada de lo que forma parte de la realidad finita, mundana y humana es extraño o extranjero a Dios y, consecuentemente, al discurso de la teología. Todo lo que constituye nuestra finitud, mundanidad y humanidad puede, por eso, prestarse para una lectura teológica ${ }^{46}$.

\section{Dios en la vida del paciente}

En este estudio, podemos ver la actuación de Dios en las personas que realmente hablan con Él, lo sienten cercano, se sienten escuchadas por Él y favorecidas por su misericordia.

Esto lo evidencian la respuesta que dieron a la petición: Háblame del Dios en el que crees: ¿Cómo es? ¿Qué características tiene? ¿Cómo se manifiesta? ¿Cómo es su presencia en tu vida? Con el pretexto de esta petición los pacientes fueron dibujando con palabras el rostro del Dios que habita sus vidas y los socorre con su misericordia.

Paciente 1 «Yo creo en Dios. Él ha sido muy bueno conmigo. A veces sufro tanto y pienso que Dios no existe y, me pregunto ¿ Dónde está? ¿Qué pasa que estoy sola? ¿̇No existo para Él? Pero he sentido la presencia de Dios, la sentí cuando me volvió a entregar a mi hijo después de sufrir un accidente gravísimo, donde pensé que no saldría vivo.

45 «Constitución sobre la sagrada liturgia Gaudium et Spes», en Concilio Vaticano II, Documentos Completos (Roma: Vaticana, 1965), No. 1, consultada en marzo 29, 2017, http://www.vatican.va/archive/hist_councils/ii_vatican_council/documents/vat-ii_const_19651207_gaudium-et-spes_sp.html.

46 Gerardo De Mori, «Una lectura teológica de la realidad. ¿̇A cuáles nuevos saberes recurrir o con qué saberes contar?», 281. 
Cuando me siento muy enferma y los médicos me mandan los medicamentos y tengo que tomarlos reniego mucho, pero siento que Dios me aterriza cuando recapacito».

Paciente 2 «Yo creo en Dios. Lo caracterizo como una energía, no lo veo como un animal, ni como una persona, ni tampoco como un objeto, más bien como una energía que viene [de] dentro de cada uno de nosotros. A raíz del vir he tenido la experiencia de que Dios ha sido mi apoyo. Es un Dios que me escucha y que se manifiesta y me ha dado mucha fortaleza. He sentido su manifestación justo cuando estoy triste y perdido, cuando no sé qué hacer. Yo mismo me hago sentir que Él está ahí apoyándome».

Paciente 3 «Yo creo en Dios. Sé que es grande y poderoso, que siempre está con nosotros. He sentido su manifestación, porque sé que estoy vivo gracias a Él. En este momento estoy de la mano de Él y en todas las cosas que hago, Él está presente. Siento que me da fortaleza».

Paciente 4 «Creo en Dios. He visto su manifestación, lo veo como un ser supremo, lo veo como el todo. Es el papá de nosotros. Es nuestra compañía. Dios se manifiesta en todo lo que existe y de una u otra manera me ha librado de muchas cosas».

Paciente 5 «Yo creo en Dios. El Dios en el que yo creo es todo lo que me rodea, vivo con Él. He sentido su manifestación muchas veces. Cuando siento que no puedo más, me ha mostrado caminos. Yo tomo la enfermedad como otro camino que Dios me dio, veo su presencia en los medicamentos. Siento que esto fue una forma que Dios me dio para cambiar, para alejarme de muchas cosas que perjudicaban mi cuerpo».

Si partimos de la premisa teológica, según la cual, «nada de lo que forma parte de la realidad finita, mundana y humana es extraño o extranjero a Dios», estos relatos constituyen, en realidad, momentos narrativos exponiendo el modo como Dios opera en la vida de estas personas. Dios se comunica con ellos y los levanta cuando arrecia el dolor, el sinsentido y la vida se vuelve insoportable. 
Dios hace que el paciente adquiera «visión interna», es decir, hace que pueda ver lo esencial y se lance a la transformación de su propia realidad y la del otro. La fortaleza del paciente de fe está en su mundo psíquico, está en su mundo interior donde habita Dios. Y por tratarse de hombres y mujeres religiosos diríamos que su fuerza deriva de la relación estrecha entre mundo psíquico personal y divinidad.

En los relatos se puede advertir que Dios se torna una especie de conocimiento fundamental, le advierte al sujeto los mecanismos de supervivencia que salen a la luz cuando todo parece perdido. Los pacientes no son personas ilustradas, sin embargo, son capaces de encontrar en Dios el conocimiento oportuno que les ayuda a sobrevivir y redimensionar su vida.

Obviamente aquí la fe adquiere una dimensión que poco o nada se parece a la fe de los académicos. Se trata de la fe que caracteriza al niño de pecho que confía en la bondad de su madre. Estamos ante la fe de seres humanos que sin más argumento que su propia experiencia creen y confían en Dios como el niño que se siente amado a hombros de su padre. No se trata de una fe razonada, ni tampoco argumentada; es más, se trata de una fe no consciente a ojos de quien la está viviendo. Solo quien ve al que cree puede decir una palabra acerca de lo que ve y, esto es precisamente, lo que intentamos plasmar aquí.

Algunos textos sagrados como la Biblia o el Corán son precedentes testimoniales de este tipo de fe. Estos textos narran la fe de hombres formidables como Abel, Noé, Abraham, Moisés, Jesús de Nazaret, Mahoma, entre muchos otros que bajo el influjo de la fe lo entregaron todo y emprendieron proyectos humanos a gran escala que hoy afectan a millones de seres humanos en el planeta. Se trata de hombres de fe que dejaron para la posteridad el testimonio vivo del poder de la fe en la vida de una persona. A manera de preámbulo y con el ánimo de espigar las características de este arquetipo de fe recurrimos a la Biblia y al Corán.

Creo que este modo de proceder nos puede ayudar a comprender la fe de los pacientes. Se trata de la misma fe, la fe en el Dios del 
monoteísmo vivida en escenarios geográficos e históricos distintos, pero al fin y al cabo, enfocada en la misma fuente y el mismo objeto de fe, el Dios de la historia y de la revelación. Los relatos presentan una fe que se ve, se trata de una fe que está a la vista de todos. Por otra parte, se trata de una fe capaz de provocar el poder de la divinidad a favor del creyente.

De otra parte, los relatos dejan percibir una característica sutil de la fe: crece como las semillas. También transparentan una fe que otorga vida: «el justo vivirá por la fe» (Rom 1, 1-17).

\section{Reflexiones finales}

La primera conclusión a la que se llega después de profundizar en los datos es que la importancia que ha adquirido Dios en la vida de estas personas es conmovedora. Sin importar que sea el Dios del amor o un Dios castigador, el 72\% de la población sujeto de este estudio cree en Dios. Pese a la adversidad, pese a haber sido golpeadas seriamente en su estructura vital por el VIH-SIDA, sinceramente creen en Dios y viven una relación cercana con Él.

Según su propio testimonio, Dios se comunica con ellos y los levanta cuando arrecia el dolor, la soledad, la indiferencia, la discriminación y el sinsentido. Según ellos, Dios ha perdonado su falta ${ }^{47}$ y los involucra como un padre involucra a su hijo en sus proyectos, los hace artífices de su destino. Hace que adquieran visibilidad para sí mismos cuando se valoran como hijos suyos. Hace que se reconcilien con sus recuerdos y enfrenten el futuro con esperanza.

De igual manera se puede concluir que, desde su fe en Dios, son personas que han configurado una espiritualidad ${ }^{48}$, un modo de ser, de pensar y de actuar de cara a la divinidad que los lleva a enfrentar la

47 La falta: con ello se refieren a que Dios los ha perdonado por haber contraído el viH-SiDA debido a prácticas sexuales indebidas.

48 Este concepto se asume en el sentido teológico de «vivir desde el Espíritu». Anselm Grün, Las fuentes de la espiritualidad, 55-79. 
vida con optimismo. Desde el punto de vista teológico, estamos frente a un hecho genuino del modo como Dios obra en la historia personal de la gente. Quizá el hecho está revelando uno de los hallazgos más significativos relacionados con el carácter terapéutico que encarna la relación paciente-divinidad. Como se sabe por otras investigaciones, una espiritualidad derivada de la fe en Dios, tiene el potencial suficiente capaz de afectar positivamente la salud física y psicológica de las personas. Investigadoras como la Dra. Nasarre han visto en la espiritualidad un recurso lo suficientemente efectivo a la hora de llevar a cabo prácticas de cuidado y sanación de las personas. A partir de estos dinamismos propios de la espiritualidad, tales como la capacidad de conectarse con el mundo y con los demás, de construir sentido, de cultivar valores fundamentales y de llevar a cabo una vida religiosa en función de un objeto de sentido (divinidad u otro tipo de realidad), una persona puede sanarse, resignificar su vida y ser protagonista de acciones significativas en beneficio de los demás ${ }^{49}$.

Desde el punto de vista metodológico, se puede concluir que la cercanía que se logró entre los participantes del proyecto, a través de los talleres, fue determinante para generar una relación donde fluyó la apertura y la confianza para poder contar la vida. Y, a su vez, contar la vida supuso generar cambios significativos en las personas. Por ejemplo, fue posible observar pacientes que fueron capaces de romper los lazos de la asfixiante soledad a la que venían atados por años. El taller fue el escenario, en el que pudieron exponer sus puntos de vista y cotejarlos con los de los demás. Se dio el caso de pacientes que fueron capaces de pasar de una comprensión genital de la sexualidad a una comprensión más holística en perspectiva de comunión y compromiso consigo mismo y con el otro. También, investigadores que cambiaron miedo por solidaridad, amistad y comprensión. Investigadores que cambiaron ausencia por compromiso real en procesos de formación. Se sembraron semillas de misericordia. Es

49 Mercedes Nasarre, ¿̇Por qué una psiquiatra habla de espiritualidad?, consultada en mayo 10, 2015, www.youtube.com/watch?v=TWowfbQrGZ4. 
posible que todas estas acciones emprendidas sea una gota de agua en el océano, pero ya se puso la semilla, la cual, según el sentido evangélico, una vez plantada en tierra fértil crecerá y dará sus frutos que alimentarán a otros que las volverán a sembrar para comenzar nuevamente un mundo de bienestar, un «reino de Dios».

De igual manera desde el punto de vista metodológico, después de darle un orden a los datos y sopesarlos en su dimensión teológica, se puede confirmar que la IAP, es un medio formidable para viajar a la interioridad religiosa de la persona y permitirle hacer de su experiencia interior, un conocimiento que puede aprovechar para asumir una postura crítica frente a sus convicciones, sus creencias y sus valores fundamentales. Es el medio para que el paciente explicite su mundo religioso y lo oriente hacia la construcción de sentido vital. Y de ese modo cada uno pueda ser forjador de su propio destino con conciencia.

Se pudo constatar que con el método IAP, los problemas definidos, analizados y resueltos por los propios afectados toman otra orientación, otra dimensión y la persona implicada empieza a ser autogestora de un nuevo proceso, se apropia de él, y adquiere un control operativo (saber hacer), lógico (entender) y crítico (juzgar) de la problemática. Es posible ver un cambio interior de la persona y que es capaz de contagiar su entorno. Cambiar por dentro para transformar el resto dirían los teóricos de la IAP.

Con ello es posible creer en la grandeza de lo pequeño cuando se empieza a generar una acción con sentido. Es una muestra de que Dios actúa en el sentido que adquieren los eventos cuando son el resultado de un trabajo humano sincero. Cuando son el resultado de la reflexión capaz de resignificar las relaciones de la vida cotidiana.

Desde el punto de vista doctrinal, la Iglesia católica concibió la sexualidad a partir de los principios teóricos de una ética naturalista, la cual discriminaba los actos sexuales con una finalidad orientada a la reproducción. De esta manera asumió una enseñanza ascética 
de dominio de las pasiones y de la abstención de la exploración corporal como placer: «el hombre es un sujeto pasivo de sus pasiones, a diferencia de Dios que no tiene pasiones y es agente. El hombre sabio debe ser imitador de Dios y, en consecuencia, debe dedicarse a anular completamente los afectos (pathos) y las pasiones por la vía de la abstinencia» ${ }^{50}$. Aunque esta concepción no es la visión actual de la Iglesia, la transmisión de una enseñanza centrada en la moral y la subvaloración del cuerpo, ha significado para las personas sufrimiento y sentido de culpa. A la fecha, estos condicionamientos siguen siendo un lastre en la vida de las personas.

\section{Bibliografía}

Álvarez, Francisco. Teología de la salud 9. Madrid: PPC, 2013.

Baena, Gustavo. ¿Qué es la espiritualidad? Video de YouTube, 1:10:24.

Publicado por Julio Alberto Arango Mejía. Noviembre 13, 2013. Consultada en marzo 29, 2017. www.youtube.com/ watch? $\mathrm{v}=\mathrm{g} 8 \mathrm{mdFFZaBdk}$.

Baena, Gustavo. Fenomenología De La Revelación. Teología De La Biblia Y Hermenéutica. Madrid: Verbo Divino, 2011.

Berger, Peter y Luckmann, Thomas. La construcción social de la realidad. Buenos Aires: Amorrortu.

Bodelón Sánchez, Casimiro. Sexualidad y moral católica. Consultada en marzo 29, 2017. http://bloc.mabosch.info/ wpcontent/uploads/2012/07/4.2.5.5\%20SEXUALIDAD\%20 Y\%20MORAL\%20CAT\%C3\%93LICA\%20.Casimiro\%20 Bodel\%C3\%B3n.pdf.

Boff, Leonardo. La experiencia de Dios. Bogotá: Confederación Latinoamericana de Religiosos - CLAR, 1983.

50 Gabriel Jaime Montoya, «La ética del cuidado en el contexto de la salud sexual y reproductiva», Acta Bioethica 2, Vol. 13 (2007), consultada mayo 15, 2017, www.scielo.cl/scielo.php?pid=S1726569X2007000200003\&script=sci_arttext. 
Catecismo de la Iglesia Católica. Vaticano: Editrice Vaticana, 1992. «Cifras del vir en Colombia en el Día Mundial de Lucha contra el Sida». Opinión y salud.com, revista digital. Consultada mayo 15, 2017. www.opinionysalud.com/cifras-del-vihcolombia-dia-mundial-lucha-sida/.

«Constitución sobre la sagrada liturgia Gaudium et Spes». En Concilio Vaticano II Documentos Completos. Roma: Vaticana, 1965. Consultada en marzo 29, 2017. www.vatican.va/ archive/hist_councils/ii_vatican_council/documents/vatii_const_19651207_gaudium-et-spes_sp.html.

«Constitución Dogmática Dei Verbum». En Concilio Vaticano II, Documentos Completos. Roma: Vaticano, 1965. Consultada en marzo 29, 2017. www.vatican.va/archive/hist_councils/ ii_vatican_council/documents/vat-ii_const_19651118_deiverbum_sp.html.

El Tiempo.com. Consultada en mayo 15, 2017. www.eltiempo.com/ vida/salud/cifras-de-vih-en-2016-41230.

De Mori, Geraldo. «Una lectura teológica de la realidad. ¿̇A cuáles nuevos saberes recurrir o con qué saberes contar?». Teología y Vida 3, Vol. 53 (2012): 281-306.

Eckhart, Maestro. Obras alemanas. Tratados y sermones. Traducido por Ilse M. de Brugguer. Barcelona: EDHASA, 1983.

Escuela Bíblica y Arqueológica Francesa de Jerusalén. Biblia de Jerusalén. Consultada en marzo 7, 2016. www.pastoralbiblica.org/biblia-de-jerusalen-consulta-en-linea.html.

SS Francisco. Exhortación apostólica postsinodal Amoris Laetitia. Roma: Vaticana, 2016. Consultada en mayo 15, 2017. http:// w2.vatican.va/content/francesco/es/apost_exhortations/ documents/papa-francesco_esortazione-ap_20160319_ amoris-laetitia.html

Foucault, Michel. Historia de la sexualidad. México: Siglo xxi, 2009. 
Gamero, Juana. Sexualidad, violencia y cultura. Bogotá: Desde Abajo, 2013.

García Valencia, Juan Diego. Transformaciones de vida a partir de una relación personal con Dios (Tesis sin publicar). Bogotá: Pontificia Universidad Javeriana, 2014.

Gómez Orjuela, Diego. Punto de inflexión. Expresión y significado. Consultada en marzo 29, 2017. http://diegogomezojeda. blogspot.com/2010/07/punto-de-inflexion-expresion-y.html.

Grün, Ancelm. El arte Del Consuelo: Lo Que sienta bien al cuerpo y al alma, Vol. 315. Santander: Sal Terrae, 2013.

Grün, Ancelm. Las fuentes de la espiritualidad. Madrid: Verbo Divino, 2013.

Isgró, Giuseppe. «Ley de compensación, semillas del éxito- noviembre de 2011». En, Las leyes del éxito, (blog). Consultada en junio 10, 2016. http://leyescosmicasdelexito.blogspot.com. co/2011/11/ley-de-compensacion.html.

Jethá, Cacilda y Ryan, Christopher. En el principio era el sexo. Los orígenes de la sexualidad humana. Cómo nos emparejamos y por qué nos separamos. México: Paidós, 2010.

Lewin, Kurt, et al. "Investigación acción participativa. Inicios y desarrollos». En La Investigación Acción Participativa, inicios y desarrollos, compilado por María Cristina Salazar, 135-174. Bogotá: Universidad Nacional de Colombia, 2011.

López Azpitarte, Eduardo. Simbolismo de la sexualidad humana: criterios para una ética sexual. Santander: Sal Terrae, 2001.

Mafla Terán, Nelson. Función de la religión en la vida de las víctimas del desplazamiento forzado en Colombia. Madrid: Universidad Complutense de Madrid, 2012.

Martínez Vertel, Luis Rafael. «La sexualidad humana a la luz de una fundamentación antropoteológica». Reflexiones Teológicas 9 (2012): 73-94. 
«Este es el panorama del viH / SIDA en Colombia». Revista Semana (abril 2012), sección vid moderna. Consultada en junio 5, 2016. www.semana.com/vida-moderna/articulo/este-es-elpanorama-del-vih-sida-en-colombia/256926-3.

Montoya, Gabriel Jaime. «La ética del cuidado en el contexto de la salud sexual y reproductiva». Acta Bioethica 2, Vol.13 (2007). Consultada en mayo 15, 2017. www.scielo.cl/scielo. php?pid $=$ S1726-569X2007000200003\&script $=$ sci_arttext.

Múnera, Alberto. «La sexualidad desde la Iglesia Católica». Revista Javeriana 721 (2006): 12-21.

Nasarre, Mercedes. ¿̇Por qué una psiquiatra habla de espiritualidad? Video de YouTube, 59:57. Publicado por «Mindalia Televisión», octubre 3, 2014. Consultada en mayo 15, 2017. www.youtube.com/watch?v=TWowfbQrGZ4.

Panikkar, Raimon. La experiencia de Dios. Madrid: PPC, 1994.

Rahner, Karl. Curso fundamental sobre la fe. Introducción al concepto de cristianismo. Madrid: Herder, 2012.

Schmiedt Streeck, Valburga, Org. Teología y VIH y Sida en América Latina. San Leopoldo: Conselho Editorial, 2013.

Torres Queiruga, Andrés. «La Experiencia de Dios, posibilidad, estructura, verificabilidad». Revista Pensamiento 211, Vol. 55 (1999): 35-69.

Vidal, Marciano. Perspectivas de ética moral cristiana.Tomo I, (2009): 25-40. Consultada en marzo 29, 2017. www.kul.pl/rocznikiteologii-moralnej-tom-1-56-2009,art_43132.html.

Vidal Marciano. Ética de la sexualidad. Madrid: Tecnos, 1991.

Enviado: 20 de abril de 2017 Recibido: 10 de junio de 2017 